Clinical Child Psychology and Psychiatry

\title{
Randomized cluster trial of a parenting program in Chile: key mediators in the decrease in behavior problems in pre- school children
}

\begin{tabular}{|c|l|}
\hline Journal: & Clinical Child Psychology and Psychiatry \\
\hline Manuscript ID & CCPP-18-0116.R2 \\
\hline Keywuscript Type: & Original Manuscript \\
\hline Keyws: & $\begin{array}{l}\text { multiple mediation, universal prevention, child behavioral problems, pre- } \\
\text { school children, parenting }\end{array}$ \\
\hline $\begin{array}{l}\text { Parenting Training is a proven strategy for the promotion of positive } \\
\text { parenting practices and the prevention and treatment of behavior } \\
\text { problems in children. The processes that explain this efficacy are less } \\
\text { clear. The aim of this study was to assess the mediating role of } \\
\text { parenting practice modification, encouraged through the implementation } \\
\text { of a universal parenting training program, in the decrease of behavioral } \\
\text { problems in 3 to 6 year-old children. Method: A cluster randomized trial } \\
\text { was carried out in 19 educational centers in low and middle socio- } \\
\text { economic areas. 178 families received the program and 154 were in the } \\
\text { control condition. The following parenting practices were assessed: } \\
\text { positive reinforcement, involvement, inconsistency, unsuitable treatment } \\
\text { behaviors and corporal punishment, and hostility and humiliation } \\
\text { behaviors. Parent-child interaction was also assessed using an } \\
\text { observational instrument. A multiple mediation analysis was carried out, } \\
\text { identifying indirect effects. Results: Reduction of harsh discipline and } \\
\text { psychical punishment, and parental inconsistency mediated the effects } \\
\text { observed in the reduction of child behavioral problems during the } \\
\text { program. Conclusions: Within Chilean families, harsh discipline, corporal } \\
\text { punishment, and parental inconsistency are important aspects to be } \\
\text { considered in the implementation of universal parenting training } \\
\text { programs. }\end{array}$ \\
\hline
\end{tabular}

\section{SCHOLARONE Manuscripts}




\begin{abstract}
:
Parenting Training is a proven strategy for the promotion of positive parenting practices and the prevention and treatment of behavior problems in children. The processes that explain this efficacy are less clear. The aim of this study was to assess the mediating role of parenting practice modification, encouraged through the implementation of a universal parenting training program, in the decrease of behavior problems in 3 to 6 year-old children. Method: A cluster randomized trial was carried out in 19 educational centers in low and middle socio-economic areas. 178 families received the program and 154 were in the control condition. The following parenting practices were assessed: positive reinforcement, involvement, inconsistency, unsuitable treatment behaviors and physical punishment, as well as hostility and humiliation behaviors. Parent-child interaction was also assessed using an observational instrument. A multiple mediation analysis was carried out, identifying indirect effects. Results: Reduction of harsh discipline and physical punishment, and parental inconsistency mediated the effects observed in the reduction of child behavior problems during the program. Conclusions: Within Chilean families harsh discipline, physical punishment, and parental inconsistency are important aspects to be considered in the implementation of universal parenting training programs.
\end{abstract}

Keywords: multiple mediation, parenting, universal prevention, child behavior problems, preschool children. 


\section{Introduction}

Parenting training has been shown to enhance the welfare and psychosocial development of children and, to prevent and treat various psychosocial and mental health difficulties (Scott \& Gardner, 2015). This type of intervention has the highest level of efficacy evidence for prevention and treatment of behavior problems and disorders (Fonagy, 2015; Scott, 2015). In spite of these successful results, there are still relevant challenges to be addressed. The most successful and developed parenting training programs have been assessed, by and large, by their own developers and therefore, more independent replications are required (Greenberg \& Riggs, 2015). They also require more evidence of their effectiveness when implemented in the context of usual services provided to the community, their sustainability and of the impact in their results when they are scaled up (Marchand, Stice, Rohde, \& Becker, 2011). The study of these programs in low- and medium-income countries is also important since they have been developed and implemented primarily in high-income countries (Knerr, Gardner, \& Cluver, 2013). Both targeted prevention and treatment programs have shown the best results but we need more evidence regarding the effectiveness of universal programs (Hiscock et al., 2008).

In addition to evidence of effectiveness, we also need to understand the mediating processes leading to successful outcomes. This research has been increasing in relevance since the first studies in 2000 (Fagan \& Benedini, 2016). A fundamental and primary aspect of these analyses is to establish whether the change in parenting practices is related to the effects of parenting training programs in terms of the prevention and the treatment of behavior problems or whether these effects result from (or are complemented by) other factors (Forehand, Lafko, Parent, \& Burt, 2014; Sandler, Schoenfelder, Wolchik, \& MacKinnon, 2011). More specifically, it is of interest to identify those parenting practices more directly implicated in the observed effects. 
It is difficult to draw conclusions based on the results of previous research. Methodological and statistical procedures to establish mediation are diverse and have also been modified in important ways over time. Many studies were carried out using the classical approach of Baron and Kenny (1986), which has been questioned in recent decades since it underestimates mediation effects (Patel, Fairchild, \& Prinz, 2017). Forehand et al. (2014) reviewed eight intervention and 17 prevention studies, observing that only $45 \%$ of the performed analyses showed significant indirect effects resulting from the modification of parenting practices (that is, mediating effects). Disciplinary practices and a measure consisting of global parenting practices were the ones that showed more evidence of being a mediator in these studies.

In this study, we undertake a mediation analysis of the effectiveness of a parenting program. The intervention program was called Day by Day. It was developed by the authors of this paper in order to enhance positive parenting practices, specifically focusing on early intervention and prevention of behavior problems in preschoolers. Theoretical and methodological components identified as fundamental parts of the most effective programs were incorporated in the Day by Day program: a foundation in social learning theories; the development of positive interaction skills of parents with their children; and the use of several strategies to enhance adherence (Gardner et al., 2009; Kaminski, Valle, Filene, \& Boyle, 2008). A more detailed description of this program, as well as the method of this cluster randomized clinical trial and its overall effectiveness, appears elsewhere (Rincon et al., 2018).. The primary outcomes of this trial were the frequency of disruptive behaviors and the concern they cause for the mother or father. In the current analysis, we aimed to identify parenting practices (potential mediators) with the greatest independent effect on the primary outcomes. For this, a multiple mediation analysis procedure was used. 


\begin{abstract}
Method
Centers

Nineteen education centers participated in this study. Eight centers were only for children aged 0 to 5 years. These centers belong to two kinds of public institutions. The others 11 centers were either public schools (six centers) or private schools (five centers) but with public funding. Most of the study population was from low socioeconomic strata. However, there were some middle class families in some of the private schools.
\end{abstract}

\title{
Participants
}

All mothers, fathers or caregivers from the relevant education centers' years (2 to 6 years) were invited to participate in the study. In each education center a open meeting was carried out, where the study was presented. In this meeting it was explained that the program could be useful for all mothers, fathers and caregivers of children. Although 416 families initially agreed, it was not possible to conduct the assessment on all of them. This was done before randomization; therefore, those who received the initial assessment (332) were considered participants of the research. Most of the participants were the children's mothers (87\%); in 14 cases more than one person attended some sessions (in most cases, both parents) but only caregivers considered as the primary ones were considered in the assessments and included in the analysis. Families selfreported who was the primary caregiver.

Ten centers with a total of 178 participants were assigned to the Day by Day program, consisting of mothers of 94 boys $(52.8 \%)$ and 84 girls (47.2\%) with an average age of 3.7 years $(\mathrm{SD}=1.0)$; parents' mean age was 30.6 years $(\mathrm{SD}=6.8)$. Nine centers with a total of 154 participants were assigned to the wait list condition, consisting of 81 boys (52.6\%) and 73 girls (47.4\%) with an average age of 3.9 years $(\mathrm{SD}=1.0)$; their mothers were 31.5 years old $(\mathrm{SD}=6.9)$ on average. The number of participants per cluster ranged from 13 to 23 . 


\section{Randomization}

The randomization of the centers was performed after inviting the participants to be part of the research and conducting a baseline assessment. At the time of the pre-test assessment, participants and evaluators did not know who would participate in each group. Stratified randomization was done according to the institutional membership of the centers. For each institution, the names of the centers were written on small sheets of paper and put inside an opaque box, from which they were randomly drawn. The first half of the selected centers were assigned to the experimental group and the remaining ones to the control group. In the case of private schools, which was an odd group, it was previously decided that three centers would be assigned to the experimental group and two to the control group. Thus, 10 centers in total were assigned to the experimental group and nine to the control group.

\section{Training Program}

The Day by Day Program contains the following seven components: affective communication; daily and child-directed play; directed attention; routines and transitions; reinforcement and incentive programs; planned inattention-ignore and time out; and logical consequences. The implemented version of the Program had six two-hour weekly sessions. It was completely manualized and was implemented during the months of May through July of 2016. It was delivered by psychologists who were trained by the research team in a 40-hour program (26 faceto-face hours). They had to approve the acquisition of the skills required in a performance assessment. This assessment consisted in the performance of a part of one randomly selected session in front of people, who played the role of participants from a group of mothers, fathers and/or caregivers. Skill acquisition was assessed by two experts using a rubric that allowed appreciating the following aspects: a) effective communication, b) leadership, c) problem 
solving, d) interpersonal sensitivity, e) relationship development and/or maintenance and e) adherence to the intervention protocol.

\section{Measurements}

The pre-assessment was carried out four weeks before the beginning of the Program at each center and the post-assessment, between five and six weeks afterwards. Evaluators were blind to the condition of the participants. Every instrument was completed by the participating adult, except for one observational instrument that was used in order to assess the interaction of the child with the adult.

Alabama Parenting Questionnaire (APQ) (Shelton, Frick, \& Wootton, 1996). This is a self-report instrument where the mother or father self-assesses the frequency with which he/she shows certain behaviors toward the child. With adaptations, it is a suitable instrument for preschool families (Clerkin, Marks, Policaro, \& Halperin, 2007; de la Osa, Granero, Penelo, Domenech, \& Ezpeleta, 2014). This questionnaire has been modified in order to be used with families in Chile, where it was shown to have good psychometric properties (Cova et al., 2017). The positive reinforcement (6 items), involvement (7 items) and inconsistency ( 7 items) sub-scales were used. Each item has five response options ( $1=$ not much to $5=$ always $)$. The internal consistencies of each sub-scale in the initial assessment were $0.52,0.69$, and 0.75 , respectively. Harsh Discipline Practice List (HDPL) (Flores \& Herrera, 2014): This 19 item scale measures harsh discipline behaviors, verbal maltreatment, and physical abuse and punishment. On the basis of an exploratory factor analysis, four items were removed because they affected internal consistency or they were cross-loaded. Two factors were identified: 1) harsh discipline and physical punishment (9 items) and 2) humiliation behaviors (6 items). The internal consistency of each sub-factor in the initial assessment was 0.77 and 0.63 , respectively. 
Keys to Interactive Parenting Scale (KIPS) (Comfort, Gordon, \& Naples, 2011). This is an observational instrument, which evaluates the quality of parenting practices with children aged 24 to 71 months. The interaction is filmed during a 15 to 20 minute play session and afterwards coded by a trained and accredited evaluator. Psychometric studies show that the instrument has acceptable internal consistency and inter-judge agreement in its scoring (Inostroza et al., 2014). Five percent of these assessments were coded again by an experienced evaluator and a discrepancy of only $5.4 \%$ was seen. It showed an internal consistency of $\alpha=0.77$ in the initial assessment. Eyberg Child Behavior Inventory (ECBI) (Eyberg \& Pincus, 1999; Garcia-Tornal et al., 1998): This is a 36-item instrument, which uses parental report to assess behavior problems in children aged between two and 16. It has an intensity problem scale with seven Likert format response options, which measures the frequency of behavior problems and a problem scale with two response options (Yes/No), which assesses the extent to which each problem is a concern for the informant. In the initial assessment, it showed an internal consistency of $\alpha=0.91$ for both scales.

\section{Ethical considerations}

The research protocol was approved by the Research Ethics Committee of the author's University. When potential participants were asked to give informed consent, they were told they would participate in the Day by Day program, either at the end of the initial assessment process (experimental condition) or in the following year semester (control condition).

\section{Data analysis}

Data analysis was performed in R version 3, using packages lme4 (Bates, Maechler, Bolker, \& Walker, 2015) $\square$ and mice (Van Buuren \& Groothuis-Oudshoorn, 2011) $\square$. 
The mediation analysis was carried out on an intention-to-treat basis, which includes every participant who is randomized, irrespective of non-compliance, withdrawal or anything that occurs after group assignment. The mediation analysis allows analyzing the causal path expected for the intervention; i.e., that intervention changes several parental practices, and these affect children's behavior. This analysis allows for the decomposition of the total effect of the intervention on children's behavior into two parts: the indirect effect, which refers to the changes on the children's behavior caused by changes in parental practices; and direct effect, which comprises changes related to the intervention, not attributable to parental practices. The recommendation for those situations where there are several potential mediators is to implement a multiple mediation model. This enables adjustment of the individual mediators from the effects of the other mediators (Hayes, 2013). This means we can examine the effect of each mediator, contingent on the presence of other possible mediators, rather than testing each potential mediator in isolation. Two parallel multiple mediation models were implemented. The dependent variables were the two trial outcomes: the frequency of behavior problems for the first model, and the concern they cause for the mother or father for the second. The potential mediator variables for both models were: positive reinforcement, involvement, inconsistency, unsuitable treatment behaviors and physical punishment, as well as hostility and humiliation behaviors. First, the existence of a total indirect effect, corresponding to the added effect of all putative mediating variables, was studied; and, second, the existence of specific indirect effects was evaluated. It is necessary to do both analyses, because it is possible to find a non-significant total indirect effect, resulting from strong effects operating in opposite directions. Also, the analysis of specific indirect effects allows one to identify the strongest mediators (Preacher \& Hayes, 2008). The calculation of the coefficients was performed using an intercept-slope 
hierarchical linear model (HLM). The fixed effects model for the calculation of the mediation was based on the regression models for two MacKinnon's waves (MacKinnon, 2008). A Wald test was performed, analogous to an ANOVA for missing data analysis (Rubin, 1987) $\square$, to test if parental practices and group effects significantly predicts behaviors problems and parental concerns. As no direct translation of $\mathrm{R}^{2}$ is available for mixed-models, the $\mathrm{R}^{2}$ S\&B-1 index was used. This accounts for reduction of variance at individual level accounted by predictors (Luo \& Azen, 2013).

The effect of the control group versus the experimental group was adjusted considering the pre-test value, sex, and the age of the child. The mediation effect was calculated by multiplying the effect of the program on the parenting practice measured in the post-test and the effect of the parenting practice on the frequency of behavior problems or in the concern they cause. The differences in pre-test values among centers, a possible higher variability in post-test within the experimental group and the differences in the relationship between pre and post-test by center, were considered as random effects. As statistical test of the indirect effects, the bootstrap confidence interval was used on the product of the regression coefficients of parent practices on intervention by the regression coefficients of children's behavior on parent practices (MacKinnon, Lockwood, Hoffman, West, \& Sheets, 2002). Bootstrapping is a computer-based procedure to estimate, without theoretical calculations, the standard errors and confidence intervals for specific parameters, using multiple random samples drawn with replacement from the original data (Efron \& Tibshirani, 1993). We used the BCA bias correction, which gives more precise confidence intervals by taking account of the asymmetric distribution of the product of the coefficients (MacKinnon, Lockwood, \& Williams, 2004). 
There are complete data for all participants for the pre-test. For post-test, 39 participants were not available (11.7\%). Due to the presence of missing data, multiple imputation was used with 20 imputed datasets. To calculate the confidence intervals considering multiple imputation, 1000 non-parametric bootstrap multilevel samples were drawn for each imputed dataset, according to the method called MI Boot pooled (Schomaker \& Heumann, 2018).

\section{Results}

Statistically significant differences were found in the experimental group between pre- and posttest with regard to: behavior problems, concern for this behavior, parental involvement, parental inconsistency and, harsh discipline and physical punishment (Table 1). However, in the control group, the only statistically significant differences between pre and post-test were a decrease in behavior problems and concern for this behavior.

\section{Path models for parental practices as mediators}

Figure 1 shows the path models for the mediation of parenting practices in the relationship between the independent variable - control and experimental group membership - and frequency of behavior problems. Coefficients $\mathrm{a}_{1}$ to $\mathrm{a}_{6}$ represent the standardized differences between the control and the experimental groups for each parenting practice. Coefficients $b_{11}$ to $b_{16}$ represent those standardized beta coefficients from the multiple regression of parenting practices on behavior problems, indicating by how many standard deviations the frequency of behavior problems increases or decreases when each parenting practice is modified by one standard deviation (keeping other practices constant).

Figure 2 shows the same path models, but this time for the outcome parent concern about the child's behavior problems. Coefficients $\mathrm{a}_{1}$ to $\mathrm{a}_{6}$ are identical to those in Figure 1, while 
coefficients $b_{21}$ to $b_{26}$ represent the standardized beta coefficients from the multiple regression of parenting practices on parental concern for behavior problems.

The child behavior problems model, that includes the direct effect of parent practices and experimental group, is statistically significant, $\mathrm{F}(17,6812.7)=23.092, \mathrm{p}<0.001$, and predicts a relevant amount of individual variance, $\mathrm{R}^{2} \mathrm{~S} \& \mathrm{~B}-1=0.56$. The parental concern model is statistically significant, $\mathrm{F}(17,4863.4)=30.104, \mathrm{p}<0.001$, and predicts a great amount of individual variance, $\mathrm{R}^{2} \mathrm{~S} \& \mathrm{~B}-1=0.63$.

\section{Analysis of the individual mediator models}

Higher parental involvement occurred in the experimental group in the post-test, $\mathrm{a}_{2}=.234$, CI $95 \%$ $[0.005,0.487]$, as well as a lower level of harsh discipline and physical punishment, $\mathrm{a}_{5}=-0.467$, $\mathrm{CI} 95 \%=[-0.695,-0.178]$. Regarding the relationship between parenting practices and frequency of behavior problems at the post-test, it can be seen that a higher parental inconsistency is related to a higher frequency of behavior problems, $b_{13}=0.230, C I 95 \%=[0.087,0.382]$. Just as a higher level of harsh discipline and physical punishment is related to more behavior problems, $\mathrm{b}_{15}=0.323$, CI $95 \%=[0.167,0.488]$. Likewise, in the case of parental concern for behavior problems, it can be seen that a higher level of parental inconsistency, $\mathrm{b}_{23}=0.207, \mathrm{CI} 95 \%=[0.077$, $0.360]$, as well as a higher level of harsh discipline and physical punishment, $\mathrm{b}_{25}=0.218$, CI $95 \%=$ $[0.078,0.378]$, are related to a higher concern at outcome.

\section{Overall effects on behavior problems}

With regard to the individual indirect effects, it can be seen that effects of parental inconsistency, $\mathrm{a}_{3} \mathrm{~b}_{13}=-0.051, \mathrm{CI} 95 \%=[-0.142,-0.001]$, and harsh discipline and physical punishment, $\mathrm{a}_{5} \mathrm{~b}_{15}=-$ 0.152 , CI $95 \%=[-0.281,-0.050]$, are statistically significant. 
The total effect of the intervention on behavior problems was statistically significant, $\mathrm{c}_{1}=-0.305$, $95 \%=[-.53,-.11]$. Our finding that the total indirect effect mediated by parenting practices, $\sum_{i=1}^{6} a_{i} b_{1 i}=-.216$, CI $95 \%=[-.375,-.080]$, is statistically significant, but the direct effect is not significant, $\mathrm{c}_{1}{ }^{\prime}=-.088$, CI $95 \%=[-.304, .074]$, meaning that this is a complete mediation model.

Overall effects on parental concern about behavior problems

Analyzing the specific indirect effects, it can be seen that, just as for the report of behavior problems, effects of parental inconsistency, $\mathrm{a}_{3} \mathrm{~b}_{23}=0.046, \mathrm{CI} 95 \%=[0.003,0.136]$, as well as harsh discipline and physical punishment $\mathrm{a}_{5} \mathrm{~b}_{25}=0.101, \mathrm{CI} 95 \%=[0.027,0.207]$ are statistically significant.

The total effect of the intervention on concern for behavior problems is not statistically significant, $\mathrm{c}_{2}=-0.271,95 \% \mathrm{CI}=[-0.542,0.018]$. However, given that the indirect effect, mediated

by parenting practices, is significant, $\sum_{i=1}^{6} a_{i} b_{2 i}=-.167$, CI95\% $=[-0.307,-0.041]$ and the direct effect is not, $\mathrm{c}_{2}{ }^{\prime}=-.105$, CI 95\% $=[-0.370,0.169]$, once again we have a complete mediation model.

\section{Discussion and Conclusions}

The effectiveness of universal parenting training programs is not clearly established and the processes implicated in their possible positive effects have not been sufficiently studied (Simkiss et al., 2013). 
This study focused on a parenting training program, Day by Day, which aimed to strengthen positive parenting practices, specifically focusing on early intervention and the prevention of behavior problems in preschoolers. We developed this training program based on a systematic review of existing programs, which had shown the most promising results worldwide. Its main elements are the strengthening of positive and rewarding interactions between parents and children, and the ability of parents to correctly apply social learning theories in order to promote adaptive behaviors and reduce maladaptive ones in their children. Our results showed that the changes in the primary outcomes (parent-reported frequency of behavior problems and their concern about them) were mediated by the changes in parenting practices. Specifically, two types of parenting practices showed a statistically significant mediation after adjustment for the effect of other practices in the multiple mediation model. These were inconsistent parenting practices, as well as harsh discipline and physical punishment practices.

These results confirm that the effects of the program are directly related to parental abilities that can be taught rather than to other factors, such as the change in parents' perceptions, simply as a result of participation in a program of this nature. It is particularly important that these abilities were observed as mediators in a universally implemented program, where, in principle, many parents already have suitable parenting abilities and many children do not show relevant behavior problems (Greenberg \& Riggs, 2015).

Parental inconsistency in the application of contingencies responding to the behavior of their children is decisive in the development and aggravation of behavior problems. The same occurs with harsh discipline and physical punishment, whose reduction appears in several studies as one of the main mediators of the effectiveness of parenting training programs (Beauchaine, WebsterStratton, \& Reid, 2005; Forehand et al., 2014; Fossum, Morch, Handegard, Drugli, \& Larsson, 2009). 
In Chile, harsh discipline and physical punishment are very frequently used and are usually related to inconsistent parenting practices (UNICEF, 2015), which may explain the effectiveness of the universal training program.

Positive reinforcement and higher level of involvement with the child did not show an independent effect in this study. Reductions in negative practices seem to have a greater impact than increases in positive practices (Forehand et al., 2014). However, this finding must be cautiously interpreted, since positive practices enable both the deployment and the effectiveness of other practices, such as suitable discipline or supervision. There are some studies that show effects of positive parenting (Forgatch \& Kjobli, 2016; Gardner, Dishion, Shaw, Burton, \& Supplee, 2007).

One limitation of this study is that it is based on a pre- and post-assessment, with no monitoring. Therefore, it was not possible to estimate the sustainability of the effects or to demonstrate that changes in parenting practices precede the changes in the behavior of the children. Ideally, changes in parental practices would have been measured during the trial and before the primary endpoint.

Another limitation is its dependence on self-reports. Thus, caution is needed in the interpretation of our findings given that an observational measurement of parent-child interactions did not show statistically significant changes. Similarly, it would be desirable to have an independent replication of the Day by Day program.

In spite of these limitations, the results are of interest. First, it evaluated a universal program, an unusual feature in the studies carried out to date (Forehand et al., 2014). Second, as it is common in these studies (Chacko et al., 2016), a significant proportion of parents who consented to participate, and were evaluated and randomized, did not attend any of the sessions (34\%). Nevertheless, our intention-to-treat analysis shows that the offer of the program led to significant 
benefits overall. This result is key to whether or not service planners and policy makers scale up such programs. Except for the full-longitudinal analysis, all of the other recent suggestions on mediating studies were considered (Patel et al., 2017). In conclusion, our results show that a universal parenting program is able to modify parenting practices and reduce behavior problems in children, which have potential preventive effects. The decrease of inconsistent parenting practices and, harsh discipline and physical punishment appear as important mediators of the effects of the program in reducing behavior problems in children. 


\section{References}

Bates, D. M., Maechler, M., Bolker, B., \& Walker, S. (2015). Fitting linear mixed-effects models using lme4. Journal of Statistical Software, 67(1), 1-48. doi.org/10.1177/009286150103500418

Baron, R. M., \& Kenny, D. A. (1986). The moderator-mediator variable distinction in social psychological research: Conceptual, strategic, and statistical considerations. Journal of Personality and Social Psychology, 51(6), 1173.

Beauchaine, T. P., Webster-Stratton, C., \& Reid, M. J. (2005). Mediators, moderators, and predictors of 1-year outcomes among children treated for early-onset conduct problems: A latent growth curve analysis. Journal of Consulting and Clinical Psychology, 73(3), 371388. doi:10.1037/0022-006x.73.3.371

Clerkin, S. M., Marks, D. J., Policaro, K. L., \& Halperin, J. M. (2007). Psychometric properties of the Alabama Parenting Questionnaire-Preschool Revision. Journal of Clinical Child and Adolescent Psychology, 36(1), 19-28. doi:DOI 10.1207/s15374424jccp3601_3

Comfort, M., Gordon, P. R., \& Naples, D. (2011). KIPS: An Evidence-Based Tool for Assessing Parenting Strengths and Needs in Diverse Families. Infants \& Young Children, 24(1), 5674. doi:Doi 10.1097/Iyc.0b013e3182001bd3

Cova, F., Bustos, C., Rincon, P., Streiner, D. L., Grandon, P., Saldivia, S., . . Contreras, G. (2017). Psychometric Properties of the Alabama Parenting Questionnaire Adapted to Families of Chilean Preschoolers. Infant Mental Health Journal, 38(2), 249-257. doi:10.1002/imhj.21631

Chacko, A., Jensen, S. A., Lowry, L. S., Cornwell, M., Chimklis, A., Chan, E., . . Pulgarin, B. (2016). Engagement in Behavioral Parent Training: Review of the Literature and 
Implications for Practice. Clinical Child and Family Psychology Review, 19(3), 204-215. doi:10.1007/s10567-016-0205-2

de la Osa, N., Granero, R., Penelo, E., Domenech, J. M., \& Ezpeleta, L. (2014). Psychometric Properties of the Alabama Parenting Questionnaire-Preschool Revision (APQ-Pr) in 3 Year-Old Spanish Preschoolers. Journal of Child and Family Studies, 23(5), 776-784. doi:10.1007/s10826-013-9730-5

Efron, B., \& Tibshirani, R. (1993). An Introduction to the Bootstrap. London: Chapman and Hall/CRC.

Eyberg, S. M., \& Pincus, D. (1999). ECBI \& SESBI-R : Eyberg Child Behavior Inventory and Sutter-Eyberg Student Behavior Inventory-Revised : professional manual. Odessa, FL: Psychological Assessment Resources.

Fagan, A. A., \& Benedini, K. M. (2016). How Do Family-Focused Prevention Programs Work? A Review of Mediating Mechanisms Associated with Reductions in Youth Antisocial Behaviors. Clinical Child and Family Psychology Review, 19(4), 285-309. doi:10.1007/s10567-016-0207-0

Flores, J. J., \& Herrera, L. M. F. (2014). Design and psychometric validation of the Harsh Discipline Practice List. Revista Iberoamericana De Diagnostico Y Evaluacion-E Avaliacao Psicologica, 2(38), 137-153.

Fonagy, P. (2015). What works for whom? : a critical review of treatments for children and adolescents (Second edition. ed.). New York: The Guilford Press.

Forehand, R., Lafko, N., Parent, J., \& Burt, K. B. (2014). Is parenting the mediator of change in behavioral parent training for externalizing problems of youth? Clinical Psychology Review, 34(8), 608-619. doi:10.1016/j.cpr.2014.10.001 
Forgatch, M. S., \& Kjobli, J. (2016). Parent Management Training-Oregon Model: Adapting Intervention with Rigorous Research. Family Process, 55(3), 500-513. doi:10.1111/famp.12224

Fossum, S., Morch, W. T., Handegard, B. H., Drugli, M. B., \& Larsson, B. (2009). Parent training for young Norwegian children with ODD and CD problems: Predictors and mediators of treatment outcome. Scandinavian Journal of Psychology, 50(2), 173-181. doi:10.1111/j.1467-9450.2008.00700.x

Garcia-Tornal, S., Calzada, E., Eyberg, S., Mas, J., Vilamala, C., Baraza, C., . . Trinxant, A. (1998). Inventario Eyberg del comportamiento en niños. Normalización de la versión española y su utilidad para el pediatra extrahospitalario. Anales Españoles de Pediatría, 48(5), 475-482.

Gardner, F., Connell, A., Trentacosta, C. J., Shaw, D. S., Dishion, T. J., \& Wilson, M. N. (2009). Moderators of Outcome in a Brief Family-Centered Intervention for Preventing Early Problem Behavior. Journal of Consulting and Clinical Psychology, 77(3), 543-553. doi: $10.1037 / \mathrm{a} 0015622$

Gardner, F., Dishion, T. J., Shaw, D. S., Burton, J., \& Supplee, L. (2007). Randomized prevention trial for early conduct problems: Effects on proactive parenting and links to toddler disruptive behavior. Journal of Family Psychology, 21(3), 398-406. doi:10.1037/08933200.21 .3 .398

Greenberg, M., \& Riggs, N. (2015). Prevention of mental disorders and promotion of competence. In A. Thaper, D. Pine, J. Leckman, S. Scott, M. Snowling, \& E. Taylor (Eds.), Rutter's Child and Adolescent Psychiatry (pp. 215-226). Oxford: Wiley.

Hayes, A. F. (2013). Introduction to mediation, moderation, and conditional process analysis : a regression-based approach. New York: The Guilford Press. 
Hiscock, H., Bayer, J. K., Price, A., Ukoumunne, O. C., Rogers, S., \& Wake, M. (2008). Universal parenting programme to prevent early childhood behavioural problems: cluster randomised trial. British Medical Journal, 336(7639), 318-321. doi:10.1136/bmj.39451.609676.AE Inostroza, C., Contreras, G., Cova, F., Rincón, P., Grandón, P., \& Saldivia, S. (2014). Acuerdo interjueces en el empleo de la escala observacional de prácticas parentales KIPS en una muestra de madres/niños chilenos de 36 a 71 meses Aijú, 12(14), 120-134.

Kaminski, J. W., Valle, L. A., Filene, J. H., \& Boyle, C. L. (2008). A meta-analytic review of components associated with parent training program effectiveness. Journal of Abnormal Child Psychology, 36(4), 567-589. doi:10.1007/s10802-007-9201-9

Knerr, W., Gardner, F., \& Cluver, L. (2013). Improving Positive Parenting Skills and Reducing Harsh and Abusive Parenting in Low- and Middle-Income Countries: A Systematic Review. Prevention Science, 14(4), 352-363. doi:10.1007/s11121-012-0314-1

Luo, W., \& Azen, R. (2013). Determining Predictor Importance in Hierarchical Linear Models Using Dominance Analysis. Journal of Educational and Behavioral Statistics, 38(1), 3-31. https://doi.org/10.3102/1076998612458319

MacKinnon, D. P. (2008). Introduction to statistical mediation analysis. New York: Lawrence Erlbaum Associates.

MacKinnon, D. P., Lockwood, C. M., Hoffman, J. M., West, S. G., \& Sheets, V. (2002). A comparison of methods to test mediation and other intervening variable effects. Psychological Methods, 7(1), 83-104. doi:10.1037//1082-989x.7.1.83

MacKinnon, D. P., Lockwood, C. M., \& Williams, J. (2004). Confidence limits for the indirect effect: Distribution of the product and resampling methods. Multivariate Behavioral Research, 39(1), 99-128. doi:DOI 10.1207/s15327906mbr3901_4 
Marchand, E., Stice, E., Rohde, P., \& Becker, C. B. (2011). Moving from efficacy to effectiveness trials in prevention research. Behaviour Research and Therapy, 49(1), 32-41. doi:10.1016/j.brat.2010.10.008

Patel, C. C., Fairchild, A. J., \& Prinz, R. J. (2017). Potential Mediators in Parenting and Family Intervention: Quality of Mediation Analyses. Clinical Child and Family Psychology Review, 20(2), 127-145. doi:10.1007/s10567-016-0221-2

Preacher, K. J., \& Hayes, A. F. (2008). Asymptotic and resampling strategies for assessing and comparing indirect effects in multiple mediator models. Behavior Research Methods, 40(3), 879-891. doi:Doi 10.3758/Brm.40.3.879

Rincon, P., Cova, F., Saldivia, S., Bustos, C., Grandón, P., Inostroza, C., ... \& King, M. (2018). Effectiveness of a Positive Parental Practices Training Program for Chilean Preschoolers' Families: A Randomized Controlled Trial. Frontiers in psychology, 9. doi.org/10.3389/fpsyg.2018.01751

Rubin, D. B. (1987). Multiple imputation for nonresponse in surveys. New York: John Wiley \& Sons.

Sandler, I. N., Schoenfelder, E. N., Wolchik, S. A., \& MacKinnon, D. P. (2011). Long-Term Impact of Prevention Programs to Promote Effective Parenting: Lasting Effects but Uncertain Processes. Annual Review of Psychology, Vol 62, 62, 299-329. doi:10.1146/annurev.psych.121208.131619

Scott, S. (2015). Oppositional and conduct disorders. In A. Thaper, D. Pine, J. Leckman, S. Scott, M. Snowling, \& E. Taylor (Eds.), Rutter's Child and Adolescent Psychiatry (pp. 913-930). Oxford: Wiley. 
Scott, S., \& Gardner, F. (2015). Parenting Programs. In A. Thaper, D. Pine, J. Leckman, S. Scott, M. Snowling, \& E. Taylor (Eds.), Rutter's Child and Adolescent Psychiatry (pp. 483-495). Oxford: Wiley.

Shelton, K. K., Frick, P. J., \& Wootton, J. (1996). Assessment of parenting practices in families of elementary school-age children. Journal of Clinical Child Psychology, 25(3), 317-329. doi:DOI 10.1207/s15374424jccp2503_8

Schomaker, M., \& Heumann, C. (2018). Bootstrap inference when using multiple imputation. Statistics in medicine, 37(14), 2252-2266.

Simkiss, D. E., Snooks, H. A., Stallard, N., Kimani, P. K., Sewell, B., Fitzsimmons, D., . . . Stewart-Brown, S. (2013). Effectiveness and cost-effectiveness of a universal parenting skills programme in deprived communities: multicentre randomised controlled trial. Bmj Open, 3(8). doi:ARTN e00285110.1136/bmjopen-2013-002851

UNICEF. (2015). $4^{\circ}$ Estudio de maltrato infantil en Chile: análisis comparativo 1994 - 2000 2006 - 2012. Santiago de Chile: Andros.

Van Buuren, S., \& Groothuis-Oudshoorn, K. (2011). Multivariate Imputation by Chained Equations. Journal Of Statistical Software, 45(3), 1-67. doi.org/10.1177/0962280206074463 
Table 1

Descriptive Statistics for Outcomes and Potential Mediating Variables

\begin{tabular}{|c|c|c|c|c|c|c|c|c|c|c|c|c|}
\hline & \multicolumn{6}{|c|}{ Experimental } & \multicolumn{6}{|c|}{ Control } \\
\hline & $\begin{array}{l}\mathrm{M} \\
\text { Pre }\end{array}$ & $\begin{array}{l}\text { DS } \\
\text { Pre }\end{array}$ & $\begin{array}{c}\mathrm{M} \\
\text { Post }\end{array}$ & $\begin{array}{c}\text { DS } \\
\text { Post }\end{array}$ & $\eta_{G}^{2}$ & p-value & $\begin{array}{l}\mathrm{M} \\
\text { Pre }\end{array}$ & $\begin{array}{l}\text { DS } \\
\text { Pre }\end{array}$ & $\begin{array}{c}\text { M } \\
\text { Post }\end{array}$ & $\begin{array}{l}\text { DS } \\
\text { Post }\end{array}$ & $\eta_{\mathrm{G}}^{2}$ & $\mathrm{p}$ value ${ }^{\mathrm{a}}$ \\
\hline $\begin{array}{l}\text { Behavior } \\
\text { Problems }\end{array}$ & 3.16 & 0.85 & 2.76 & 0.85 & .056 & $<.001^{* *}$ & 3.20 & 0.81 & 3.09 & 0.89 & .005 & $0.036^{*}$ \\
\hline $\begin{array}{l}\text { Parental Concern } \\
\text { for Behavior } \\
\text { problems }\end{array}$ & 1.36 & 0.21 & 1.27 & 0.22 & .040 & $<.001 * *$ & 1.41 & 0.20 & 1.37 & 0.23 & .007 & $0.001 * *$ \\
\hline Reinforcement & 4.66 & 0.35 & 4.71 & 0.35 & .005 & .090 & 4.62 & 0.36 & 4.63 & 0.36 & .001 & 0.847 \\
\hline $\begin{array}{l}\text { Parental } \\
\text { Involvement }\end{array}$ & 4.39 & 0.52 & 4.52 & 0.46 & .017 & $<.001 * *$ & 4.35 & 0.53 & 4.35 & 0.52 & .001 & 0.949 \\
\hline $\begin{array}{l}\text { Parental } \\
\text { Inconsistence }\end{array}$ & 2.48 & 0.83 & 2.23 & 0.78 & .025 & $<.001 * *$ & 2.51 & 0.77 & 2.42 & 0.74 & .003 & 0.103 \\
\hline $\begin{array}{l}\text { Humiliating } \\
\text { treatment }\end{array}$ & 0.06 & 0.21 & 0.04 & 0.13 & .002 & .180 & 0.07 & 0.14 & 0.06 & 0.12 & .002 & 0.430 \\
\hline $\begin{array}{l}\text { Harsh discipline } \\
\text { and physical } \\
\text { punishment }\end{array}$ & 1.01 & 0.5 & 0.77 & 0.4 & .073 & $<.001^{* *}$ & 1.07 & 0.47 & 1.01 & 0.5 & .004 & 0.066 \\
\hline KIPS & 3.77 & 0.78 & 3.71 & 0.78 & .002 & .436 & 3.46 & 0.72 & 3.55 & 0.74 & .004 & 0.276 \\
\hline
\end{tabular}

$\mathrm{N}=332$ a Corresponds to the result of a mixed ANOVA, with fixed effect time and random effect belonging to the educational center $* \mathrm{p}<0.05 * * \mathrm{p}<0.01^{b}$ Keys to Interactive Parenting Scale. 


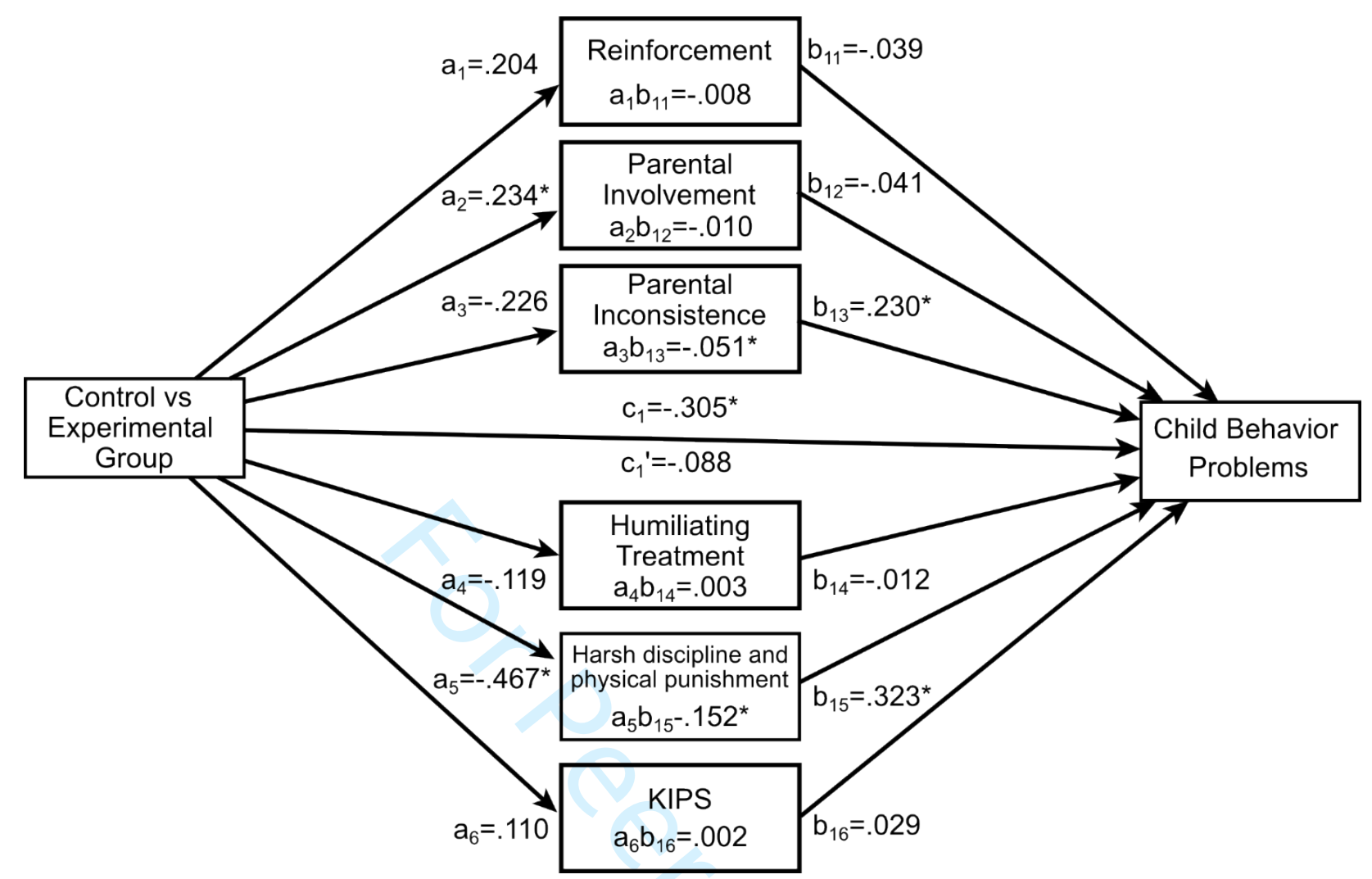

Figure 1. Results of the mediation model of parenting practices in the relationship between the effect of the treatment and the behavior in disruptive practices. Coefficients $\mathrm{a}_{1}$ to $\mathrm{a}_{6}=$ standardized differences between the control and the experimental groups for each parenting practice. Coefficients $b_{11}$ to $b_{16}=$ standardized beta coefficients from the multiple regression of parenting practices on behavior problems. Coefficients $\mathrm{c}_{1}{ }^{\prime}=$ standardized direct effect on child behavior problems. Coefficients $c_{1}=$ standardized total effect on child behavior problems. Products $\mathrm{a}_{1} \mathrm{~b}_{11}$ to $\mathrm{a}_{6} \mathrm{~b}_{16}=$ standardized indirect effects of control versus experimental group on child behavior problems through mediator parental practices. *Confidence interval of the coefficient does not include the 0 .

KIPS= Keys to Interactive Parenting Scale* 


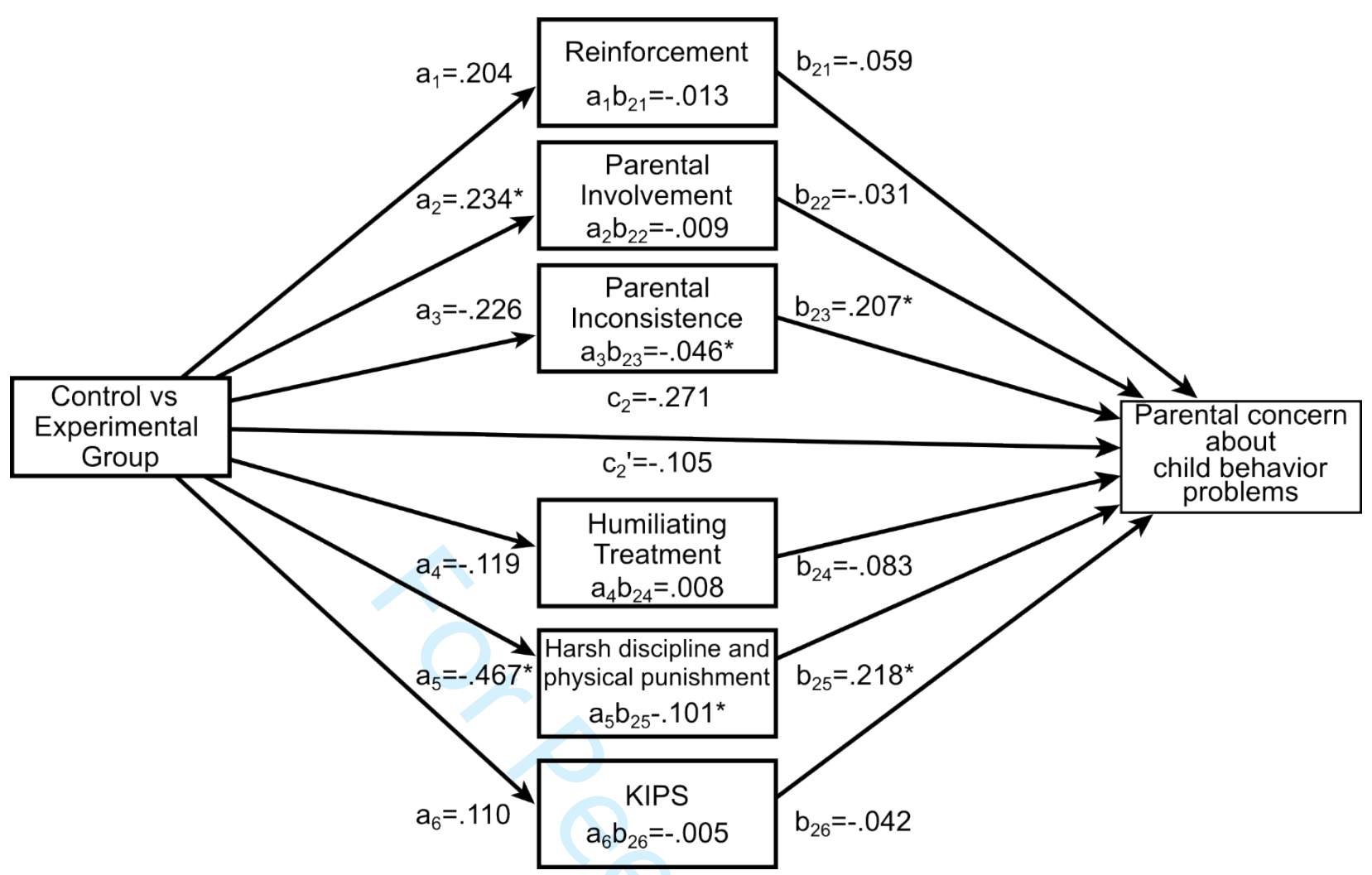

Figure 2. Results of the mediation model of parenting practices in the relationship between the effect of the treatment and parental concern. Coefficients $\mathrm{a}_{1}$ to $\mathrm{a}_{6}=$ standardized differences between the control and the experimental groups for each parenting practice. Coefficients $b_{21}$ to $b_{26}=$ standardized beta coefficients from the multiple regression of parenting practices on parental concern. Coefficients $\mathrm{c}_{2}{ }^{\prime}=$ standardized direct effect on parental concern. Coefficients $\mathrm{c}_{2}=$ standardized total effect on parental concern. Products $\mathrm{a}_{1} \mathrm{~b}_{21}$ to $\mathrm{a}_{6} \mathrm{~b}_{26}=$ standardized indirect effects of control versus experimental group on parental concern through mediator parental practices. Confidence interval of the coefficient does not include the 0 .

KIPS $=$ Keys to Interactive Parenting Scale 